\title{
A Characterization of Humans as Meta-Symbolic and Meta-Interpreting Beings
}

\author{
Hans Lenk* \\ Karlsruhe University, Germany
}

\begin{abstract}
Cassirer 's characterization of the human being as the symbolic being (animal symbolicum is analyzed and criticized and extended here in a methodological manner. A comparison with wild and trained primates regarding using tools and establishing local cultures as well as utilizing symbolic gestures and sign languages shows that the human being cannot be characterized as the only symbolic animal. Instead, we as humans can be demarcated from primates by our capability of ascending and transcending to higher meta-levels of symbolization, interpretation, cognition and language. We are rather the meta-interpreting being (animal meta-symbolicum) and super-interpreting beings transand super-interpreting.
\end{abstract}

KEYWORDS: Animal symbolicum; Meta-interpreting being; Higher meta-levels of symbolization and interpretation; Methodological interpreationism

\section{MINI REVIEW}

It was the philosopher Cassirer who characterized "man", the human being as the "symbolic animal" (animal symbolicum), i.e. the being which construes a world of symbols, orients itself in it and has to weave a net of symbols or symbolic net 1944, even living in a new dimension of reality, in "a symbolic universe". (S)he cannot confront reality directly, but (s)he has to interstice this artificial medium between him or her and reality being basically - by nature - dependent on symbolic means and capacities of representation (i.e. on culture). Already in antiquity, Poseidonius stressed the idea that "man" is by nature necessarily and indispensably dependent on culture. He would first use the expression 'second nature' as a central concept of anthropology and of his doctrine of the origin of culture [1-3].

Herder used this concept later in his theses of humans as beings characterized by deficiencies, insufficiencies and incompleteness (by the way, a contention already implicitly seen by Plato) which had been used for the development of language and culture. In modern philosophical anthropology, Plessner 1928, 1975 developed the thesis of "the second nature", i.e. culture, as highlighting the constitutive "excentricity" and homelessness of humans by the dependence on this kind of second nature and the original "homelessness of man" making cultural development and civilisation necessary. "Man" would even be "the apostate, defector of nature, the troublemaker, attention-seeker, achieving being" with all respective consequences and phenomena of a "tendency of self-aggrandizements of life in terms of the power instinct". The constitutively "ex-centric" being (locating itself besides its own centre) has to secondarily work towards the unity of life under drafts, plans and anticipations, i.e., humans have to "lead" their lives: "man as an excentrically organized being has to make himself" by not merely living according to the "law of natural artificiality", in an "artificial form of existence", but also by "leading" his life. Gehlen not only took up the thesis of the "deficient being"
Quick Response Code:

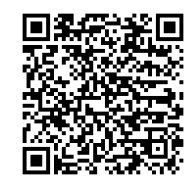

Address for correspondence: Hans Lenk, Karlsruhe University, Germany

Received: February 10, 2020 Published: March 05, 2020

How to cite this article: Hans Lenk. A Characterization of Humans as Meta-Symbolic and Meta-Interpreting Beings. 2020 - 2(2) OAJBS.ID.000149. DOI: 10.38125/OAJBS.000149 
("Mängelwesen") from Herder, but also the thesis of the "second nature of man" from Plessner: "exactly at that locus, where for an animal the 'environment' figures, stands as regards man the cultural world ('Kulturwelt'), i.e. the sector of nature overwhelmed by him and creatively altered by him to become the very supporting means of life" [4-8].

Gehlen also develops this insight within the framework of his philosophical doctrine of institutions interpreting the function and the central nature of institutions in the respective relieving import and in the functions of mediating as well as constituting and constructing artificial world structures and norms, values etc. Culture is understood as second nature. The "background" or primary nature in Gehlen takes up the role as a quasi-Kantian a priori behind the only knowledgeable and available "second nature" shaped by cultural representations of the world. Cultural means and sorts of representation (media of grasping and representing) are of course symbolic: only by symbolical representation we can and may grasp, constitute, and structure our world versions; the second nature is necessarily a "symbolic universe", it is spanned by Cassirer's "symbol net". The cultural and civilized world is a symbolically shaped world (version) [9-12].

Cassirer cites the traditional sign-theory after Peirce, Morris 1938 and SK Langer 1942 according to which in philosophy all symbols are not only vicarious substitutes for objects as a traditional interpretation of Peirce's triadic sign theory, but a "vehicle for the grasping of objects" in general serving to grasp, symbolise and interpret things or situations. Cassirer however uses this insight for the foundation of an enlarged symbolistic philosophical methodology by characterizing man as the only being which by "a symbolic imagination and intelligence" 1944: therefore, "instead of defining man as an animal rationale, we should define him as an animal symbolicum. Characteristic for the principle of this "symbolic" is amongst other functions "universality"; the general "validity and general applicability", "the magic word, the Open Sesame!" allow, by culture and its "architectural structure", the "general symbolic function" of signs and language as well as multiplicity and variability: only a highly "complex system of symbols" would render possible rational and relational thinking, human grasping, reflection, and culture and civilization [13-17].

Moreover, Cassirer refers to Herder's theory of "reflexive thinking" about the origin of human language, culture and civilisation. All these fundamental capacities and explanatory factors depend on the ability and function of using symbols so masterly and intriguingly analyzed by Cassirer in his main work Philosophy of Symbolic Forms 1923ff. Any grasping and "objectification", even representations of nature states are only to be covered by "constructive process(es)", dependent on "symbolic constructs". Even "all classification systems are artificial. Nature as such does contain only individual, multifarious phenomena. By abstracting and summarizing as well as conceiving these phenomena under concepts of sets and general laws, we do not describe natural facts. "Every system is a work of art" - a result of "conscious creative activity". "Theoretical" work would always mean "constructive work": "spontaneity and productivity is the very center of all human activities. It is man's highest power and it designates at the same time the natural boundary of our human world. In language, in religion, in art, in science, man can do no more than to build up his own universe - a symbolic universe, that enables him to understand and interpret, to articulate and organize, to synthesize and universalize his human experience". Therefore, (only) are the symbolic beings, man the "animal symbolicum".
This symbolic being needs a "symbolic universe", into which it has to direct its projections, in which it would "live" (in a secondary meaning) and by which "the symbolic net" is extended [18-20].

Cassirer wanted to substantiate and support his philosophic anthropology of the symbolic being by a comparison with the most modern research on primates; especially would he attribute to chimpanzees (Yerkes) the ability to use signs to utilise "designators" but indeed not the capability of symbolic interpretation (with universality, functionality, variability and general language functions).This certainly was plausible at the time 1944 , but that does not hold any more nowadays, for in the meantime research on primates has advanced considerably.

Researchers taught chimpanzees like Washoe and gorillas like Koko to communicate (the latter one with more than 1000 "words", "concepts" or "meaningful gestures") in American Sign Language (A. and E. Gardner and Patterson). These primates are able by using a functional quasi symbolic combination of meaningful signs and sentence parts to combine simple sentences up to six words or so or even add and subtract small numbers (e.g. Sheba, after S Boyson). Trained primates even performed generalizations and self-reflective utterances. In addition, chimpanzees and bonobos used plastic chips or symbolic notations on computer displays in combination games like "Scrabble" as Savage-Rumbaugh experimentally proved with the chimpanzees Austin and Sherman as well as with the real primate genius, the bonobo Kanzi, and his sister Panbenisha. Washoe, Koko and Kanzi not only occasionally played the fool, but also made a fool of the respective interviewing partner or experimenter [21-23].

For instance, Koko, the gorilla, communicated with American Sign Language the wrong answer "red" of a white handkerchief, laughing and necking the experimenter Patterson. The latter one was annoyed and wanted to give up already. Koko then picked suddenly, a very tiny red thread from the handkerchief and signaled laughingly "Red, red, red!" Chimpanzees and bonobos are not only able to use and even produce tools (e.g. to put together bamboo sticks to get at bananas in the distance as W Koehler had already substantiated in his famous early primate experiments, but they are also able creatively to apply tools to a respective situation type and single situations. They are also capable of using in a limited sense at least means of representation to transfer and in a sense generalize them referred to other situations. They are able consciously to make a fool of somebody, to betray or deceive partners and rivals (De Waal, Sommer). They even developed an elementary "culture" by establishing a certain tradition of learned and discovered uses of instruments and tools. Famous is the macaque "girl" Imo in Japan which had discovered that potatoes would taste better after they had been washed in saltwater [24-27].

Imo's washing activity soon spread out over the whole macaque colony and even to a neighboring one. Ch. and H Boesch 1991 observed chimpanzee mothers carrying instruments as, e.g. a stone, which they used to open nuts (19 types of tool use and 6 ways of making tools were recorded with chimps in Taï National Park, Ivory Coast.). The opening was taught to the youngsters which had for quite a while really to learn and practice a certain kind of skill to be able to crack a hard nut. The mother occasionally hid such a tool and carried it along - defending and/or reclaiming it even as some kind of "private property" - when migrating to another feeding place. This seems to be local "culture" - because there was also a spreading of this utilization of tools displaying in some sense symbolic functional meaning (including a certain limited 
generalization). Whereas in Senegal wild chimpanzees also used sticks and branches to dig for termites (Wrangham), respective groups of chimpanzees in Uganda did not develop this cultural utilization of a sophisticated tool, although they had also termite heaps available. Sugiyama 1981 in Cameroon even observed how chimpanzees using tools to make tools with several functions: like using a sharp cutting stone or so to make a point for boring at one end of the twig and to hammer with a stone the other end to form a certain kind of brush to retrieve the termites by putting this end into the hole bored before. Primates not only use tools, but they also understand a certain kind of general function of tools and they even use tools to make tools, thereby falsifying Franklin's thesis and definition of man as the (only) toolmaking animal $[28,29]$.

Primates are therefore able to generalize and again individualize functions of learned utilizations of tools and to specify meanings of symbols and gestures by establishing little local-cultural traditions etc. They even discover or invent new artifacts or activities which in a limited sense might spread throughout the local colony or even neighboring groups. Thus, the utilization of tools and symbols is not only characteristic for humans, but also in a limited sense to be found in wild living primates. They can engender gestural signs which they use in a symbolic way or even generalize in some (though also rather restricted) sense. Thus, they use, to a certain degree, symbols. Therefore, they are also within some limits "symbolic beings" or capable to understand sign combinations as symbols and to use them systematically for the control of behavior and reaction. This is especially true for the highest primates like chimpanzees, gorillas and the bonobos as was confirmed by observation of wild living primates or experiments with trained ones. (Some studies of "animal languages" with dolphins by Lilly, Pryor and Herman or "individualized" singing recognition patterns with birds' pairs seem to substantiate the use of communication gestures and symbols also with other species). The activities imply certain symbolic representations for grasping their functional "meaning" and manipulating as well as controlling behavior - even including self-reference, reflexivity, and (sign) reciprocity (at least with chimpanzees, bonobos and orang-utans); they may also in a limited sense perform transfers or generalizations and some kind of inferential discrimination as well as simple logical inferences like exclusions or even contrapositions.

All that would mean that Cassirer's restriction of the use of symbols and the capacity to establish and generalize as well as individualize symbolic articulations, representations and networks as being unique for humans and his attempt to characterize "man" just by this symbolic ability or function turns out to be too rash, if not wrong. This thesis must be modified. However; these primates certainly do not again analyze these symbols or symbolically "understood" functioning signs as some new objects of a symbolic analysis on a higher level (meta-level). This is particularly true for the gestures and signs as well as activities which are not genetically fixed but "culturally" developed, so to speak. They do not make the symbols and the utilization of them (including the rules of symbol use and symbolic functions) again an object of a higher (meta)level symbolic representation. They do not again analyze and symbolize the application of signs per se. This seems to be a characteristic trait for the human being that (s)he is able to not only apply symbols on a higher meta-level but also to designate, "mean" and interpret the utilization and function of symbols in a higher-level representative form and analysis. Only humans can ascend to higher symbolic levels in a rather unlimited manner.
To my mind, the human being is the only being who may - without restriction - establish levels and meta-levels of symbols and signs to symbolize and refer to lower-level symbols and represented objects (again in the form of a kind of object representation).(S)he is able to perform a sort of "symbolic ascent"(see my 2000), go to higher and abstract levels, to vary, again "objectify", i.e. symbolically and abstractly designate, lower-level activities and symbolizations in the form of new, higher-level symbolization processes and activities. Procedures of checking, evaluating, controlling, and planning actions in the sense of an anticipatory situation-transgressing towards future action patterns are necessarily represented or incorporated by symbols in processes of symbolization (symbolic representation) within cultural activities of structuring and interpreting norms and signs. To make it short: the human being is not only the sign-using symbolic being inventing, fashioning, varying and utilizing symbols and representing by symbols, but it is the being which projects, establishes and changes symbols as the objects of higher-level symbolization processes, i.e., it interprets these construed artificial "objects" on a meta-level. Humankind is not just the species which uses symbolic forms, but the very and only one reflecting and projecting as well as varying symbols about and over symbolic signs and symbols as well as symbolization processes. The human being therefore is not only the animal symbolicum but the animal meta-symbolicum. Only the human being is capable of not only creating and using meta-symbols as well as interpretations and meta-interpretations - (s)he is the animal super(inter-)pretans et symbola symbolisque creans. (S)he transgresses the realm of mere sign utilization and symbolic functions by trans- and superinterpreting, symbolically transcending these forms and usages in a reflexive manner. (S)he is the being potentially able to transgress any levels of representation towards ever-accumulating higher meta-levels varying, projecting, reflecting or rejecting "meaning", schematizing and structuring as well as ordering and analyzing in short: interpreting - representations of the (mostly proximate) next-lower level.

The human being is the being of meta-levels. It can transcend beyond different meta-levels of language by higher-level symbolization and interpretation. If we refer to the transgressing of sets within one and the same level by the Latin syllable 'trans' and to the ascending to higher-levels by 'super' or 'supra', we can call the human being the trans-interpreting and/or super- or suprainterpreting being, or for short: the meta-interpreting being, the level-transgressing interpreting being and by that in turn really the (meta-)reflecting being. Abstract reflections are only possible if you can transcend the actual level at hand, if you can transgress the levels by going meta-symbolic or super-interpreting. Therefore, it is most plausible to notify the human being as the "animal metasymbolicum" (a sort of extension of Cassirer's terminology) or as the super-interpreting being (in extension of Nietzsche's conception of the interpreting being).

Meta-levels and even methodological interpretations or analyses of reflective and interpretative levels (so to speak metalevels of interpretations) can well be coordinated with or even integrated within this approach. The interpretative levels of interpretation using higher-level symbols for representation is certainly open with respect to an ever-transgressing and ascending leveling of symbolizations upwards. One may again in a cumulative combination so to speak incorporate these higherlevel interpretations in the talk of the "interpreting being". I think Nietzsche and Cassirer certainly would have included the higherlevel symbolic functions and utilizations in their approaches. 
However, to avoid terminological misunderstandings and difficulties of level interpretation etc., it seems to be better to talk of "animal meta-symbolicum" or the "trans-interpreting and suprainterpreting" or "super-interpreting" being.

It is certainly not hypostatized nor explicitly contended that this anthropological feature would be the only one: earlier, I tried to develop a practice-oriented philosophical anthropology of rather pluralistic provenance, based not on just one unique factor, but a multi-factorial and multi-functional philosophical anthropology taking into consideration many results of empirical disciplines 2010. A philosophical anthropology should not only be based on just one trait in a monolithic manner. The capability of transcending and ascending to ever higher-levels and meta-levels of interpretation may be a really unique characteristic of humans well-suited to demarcate the higher(-level) human culture as a realm of meta-symbols and meta-interpretations, though not as the only function for the constitution, development, and foundation of our "second nature" (i.e. "culture"). To be sure, this feature of metainterpretation is central and indispensable, essential and unique for humans, but it is certainly not the only characteristic feature.

To summarize again: One may understand and demarcate, or distinguish, man from higher animals - including especially primates - by identifying and characterizing the human being as the animal meta-symbolicum or as meta-representing, meta-interpreting, trans- and supra-interpreting ("super-interpreting") being. It is the meta-level being of representations and interpretations - as well as the being of meta-cognitions and meta-actions - in short: human beings are the meta-level beings par excellence. Only they can develop, open, ascend to several higher (meta)levels of symbolization and abstraction - and identify with/by such higherlevel characterizations. Humans are higher-level symbolists.

\section{REFERENCES}

1. Bateson G (1982) Natur und geist. Frankfurt, Germany.

2. Bateson G (1985) Ökologie des geistes: Anthropologische, psychologische, biologische und epistemologische perspektiven. Frankfurt, Germany.

3. Becker PR (1993) Werkzeuggebrauch im tierreich. Stuttgart, Germany.

4. Bischof N (1985) Das Rätsel ödipus: Die biologischen wurzeln des urkonflikts von intimität und autonomie. Munich/Zürich, Germany.

5. Boesch CH (1991) Dim forest, bright chimps. In: Natural History 9: 5057.

6. Boesch CH (1990) Tool use and tool making in wild chimpanzees. Folia Primatologica 54: 86-99.
7. Cassirer E (1923) Philosophie der symbolischen formen. 3 (I: Oxford 19562. II. Darmstadt: WBG 19772, III: 19644).

8. Cassirer E (1944) Essay on man. Frankfurt/M, Germany.

9. Cassirer E (1977) Wesen und wirkung des symbolbegriffs. Darmstadt: WBG.

10. Fouts R, Mills ST (1998) Unsere nächsten verwandten. Munich, Germany.

11. Gehlen A (1940) Der mensch. (quoted: Bonn 1962)

12. Lenk H (1968) Kritik der logischen konstanten. Berlin, De Gruyter, New York, USA

13. Lenk H (1973) Metalogik und sprachanalyse. Freiburg: Rombach, Germany.

14. Lenk H (1993) Interpretationskonstrukte: Frankfurt/M Suhrkamp, Germany.

15. Lenk H (1995) Das metainterpretierende wesen. Allg Ztschr fur Philosophie 20(1): 39-47.

16. Lenk H (2000) Kreative aufstiege. Frankfurt/M: Suhrkamp, Germany.

17. Lenk H (2007) Global techno science and responsibility. Berlin: LIT.

18. Lenk H (2010) Das flexible vielfachwesen. Weilerswist: Velbrück. $2^{\text {nd }} E d$. 2011.

19. Lenk H (2013) Kreative pluralität. Anthropologische Perspektiven. Bochum - Freiburg: Projektverlag, Germany.

20. Lenk H (2017) Scheme dynamics. Bochum - Freiburg: Projektverlag, Germany.

21. Lenk H (2018) Human zwischen öko-Ethik und ökonomik. Bochum Freiburg: Projektverlag, germany.

22. Lethmate, J (1989) Evolutionsökologie der menschenähnlichen (Homenoidea). In: Praxis der Naturwissenschaften/Biologie 38(1): $7-15$.

23. Meltzoff AN (1988) Imitation, objects, tools and the rudiments of language in human ontology. Hum Evol 3(1-2): 45-64.

24. Plessner H (1928) Die stufen des organischen und der mensch. Berlin: De Gruyter 1962.

25. Savage R, Lewin SR (1994) Kanzi.

26. Savage R, Shanker, Taylor T (1998) Apes, language, and the human mind. Oxford UP.

27. Sommer V (1992) Lob der lüge. Munich, Germany.

28. Staal, F (1988) Rules without meaning: Ritual, mantras in the human sciences. New York, USA.

29. Trivers R (1971) The evolution of reciprocal altruism. Quarterly Rev of Biology 46(1): 35-57. 